\title{
Awareness of head and neck cancers in Saudi Arabia
}

\author{
A questionnaire based study
}

Saleh Alqaryan, MBBS, Turki Aldrees, BSc, MBBS, Sharif Almatrafi, MBBS, SB-ORL-HNS, Amjad Alharbi, BSc, MBBS, Humaid Alhumaid, MBBS, SB-ORL-HNS.

\begin{abstract}
الأهداف : لسد فجوة معرفة أنواع وأعراض سرطانات الرأس والعنق من خلال توفير بيانات وتحليلات لحالة الوعي بين البالغين السعوديين.

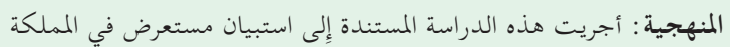

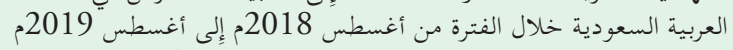

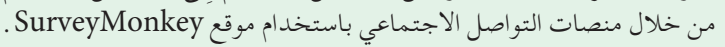

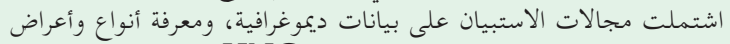

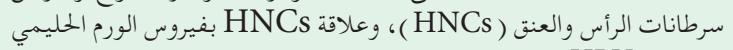
البشري (HPV) ولقاحه.

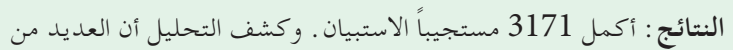

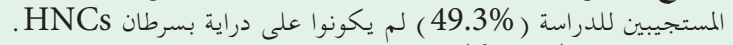

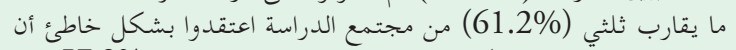

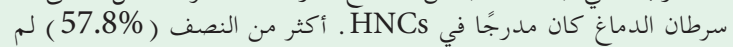

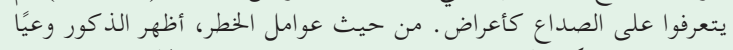

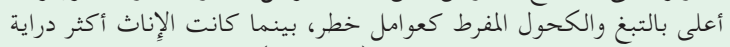

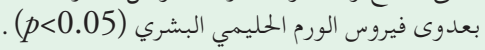

الخحلاصة : كشفت هذه الدراسة عن نقص المعرفة والوعي بالسمات الإكلينيكية

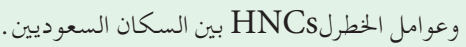

Objectives: To address the gap in knowledge by providing data and analyses of the status of awareness among Saudi adults.

Methods: This cross-sectional questionnaire-based study was carried out in Saudi Arabia from August 2018 to August 2019 through social media platforms using SurveyMonkey. The domains of the questionnaire included demographic information, knowledge of types and symptoms of head and neck cancers (HNCs), and the relation of HNCs to human papillomavirus (HPV) and its vaccine.

Results: A total of 3171 respondents completed the questionnaire. The analysis revealed that many of the study respondents (49.3\%) were not knowledgeable about HNCs. Almost two-thirds (61.2\%) of the study population incorrectly believed that brain cancer was included in HNCs. Over half (57.8\%) did not recognize headaches as a symptom. In terms of the risk factors, males showed higher awareness of tobacco and excessive alcohol as risk factors, while females were more knowledgeable about HPV infection $(p<0.05)$.

Conclusion: This study revealed that there is a lack of knowledge and awareness of the clinical features of and risk factors for HNCs among the Saudi population.

Keywords: head and neck cancers, cancers, awareness, HPV

Saudi Med J 2020; Vol. 41 (4): 400-405
doi: 10.15537/smj.2020.4.24990

From the Department of Otolaryngology (Alqaryan), King Saud University, from the Pathology Department (Alharbi), King Abdulaziz Medical City, Riyadh; from the College of Medicine (Aldrees, Almatrafi), Prince Sattam bin Abdulaziz University, Al Kharj; and from the College of Medicine (Alhumaid), Qassim University, Al Qassim, Kingdom, Saudi Arabia.

Received 7th December 2019. Accepted 4th February 2020.

Address correspondence and reprint request to: Dr. Saleh Alqaryan, Department of Otolaryngology - Head and Neck Surgery, King Saud University Medical City, Riyadh, Kingdom of Saudi Arabia. E-mail:S.qorian@gmail.com

ORCHID ID: http://www.orchid.org/0000-0002-2393-0214

$\mathrm{H}$ ead and neck cancers (HNCs) entail a group of cancers arising from the oral cavity, pharynx, larynx and nose, and paranasal sinuses. The Global Cancer Observatory (Globocon) ranked thyroid cancer as the third most common cancer in Saudi Arabia after breast and colorectal cancer. ${ }^{1}$ As a group, HNCs are considered the ninth leading cause of cancer in Saudi Arabia. ${ }^{2}$ These cancers are primarily found among the 
adult and aging population,with $98 \%$ of cases occurring in patients older than 40 years and $50 \%$ in patients older than 60 years. $^{3}$ The survival rates of HNCs range between $89 \%$ in the early stages and $27 \%$ in the advanced stages. ${ }^{4}$ Thus, it is of paramount importance that HNCs be diagnosed early. ${ }^{5}$

The diagnosis of HNCs relies heavily on the patient's history and physical examination. Using endoscopic techniques to diagnose or rule out masses is essential and usually takes place in an outpatient setting. With this in mind, patients should have a clear idea on the signs and symptoms of HNCs to allow for early recognition and management. Head and neck cancers are preventable, with estimates suggesting that more than $75 \%$ of cases in the United States are caused by tobacco use. ${ }^{6,7}$ However, other factors-including alcohol use, unprotected sun exposure, and dietary factors-can play a role in the disease pathogenesis. Human papillomavirus (HPV) infection has been established as a key element of HNCs, especially for carcinoma of oropharyngeal origin. ${ }^{8}$ Despite a decrease in the overall incidence of HNCs, the incidence of oropharyngeal cancer has markedly increased over the last 2 decades, and this phenomenon is largely due to increasing HPV infections. ${ }^{\text {? }}$

Over the past years, there has been a noticeable increase in health campaigns across the Kingdom of Saudi Arabia. These campaigns usually take place in shopping malls and venues were families spend their free time. Due to the preventability of HNCs by avoidance of risk factors and management in its early stages, enhancing the knowledge and awareness of the Saudi public would benefit both primary and secondary prevention of HNCs. However, there is a lack of studies assessing the level of awareness among the Saudi population regarding HNCs. This study aims to address this gap in knowledge by providing data and an analysis of the status of awareness among our sample. Our findings would serve as a building block and benchmark for future studies and help health committees in the country to develop and implement new tools to prevent HNCs.

Methods. In this questionnaire-based cross-sectional study, we adopted the questionnaire by Luryi et $\mathrm{al}^{6}$ with modification. The study was approved by the review board of Prince Sattam Bin Abdulaziz

Disclosure. Authors have no conflict of interests, and the work was not supported or funded by any drug company.
University, Al Kharj, Saudi Arabia. We administered the questionnaire from August 2018 to August 2019. We used SurveyMonkey to deliver the survey online to a wide range of regions in Saudi Arabia through social media platforms. The questionnaire included individuals' demographic information, social habits, and knowledge on HNCs and how it relates to HPV. Demographic information included gender, age, regions of residence, and educational status. The questionnaire's knowledge section addressed the self-reported level of knowledge regarding HNCs, their types, and the most common risk factors. Additionally, we also addressed HPV and its vaccine to check the level of awareness of this issue. The number of respondents was 3171 . We excluded healthcare professionals because these individuals have a better understanding of the subject compared to the general population. We also excluded respondents outside of Saudi Arabia.

Statistical analysis. Data were analyzed using statistical software IBM SPSS version 21 (IBM Corp. Armonk, NY, USA). Descriptive analyses with calculated measures of central tendency and variation were computed, along with frequency tables for categorical variables. We considered demographic and social habits (example, smoking and alcohol usage) variables as correlates and knowledge variables as outcomes. Pearson's $\chi^{2}$ and t-tests were used to determine the significance of association between these variables. We considered a $p$-value of $<0.05$ to be statistically significant.

Results. A total of 3171 respondents were surveyed regarding their knowledge of HNCs. Over half of the respondents were male (54\%) and ages 18 to 29 years old (67.4\%). Regarding lifestyle, $77.4 \%$ of respondents were non-smokers, and $96.3 \%$ of them did not consume alcohol. Table 1 shows the demographics of the respondents.

Most of the respondents did not consider themselves to be knowledgeable of the subject $(n=1564)$. No significant association was seen between perceived knowledge and alcohol consumption $(p=0.053)$ or tobacco use ( $p=0.779)$. Gender $(p<0.001)$, marital status $(p=0.003)$, education $(p=0.001)$, and age $(p=0.041)$ were found to be significantly associated with knowledge on HNCs.

Figure 1 shows that few of the respondents knew the different types of cancers included in HNCs. Almost two-thirds (61.2\%) of respondents incorrectly included brain cancer as an HNC. The questions on symptoms of HNCs in Figure 2 shows that over half of respondents $(57.8 \%)$ incorrectly stated that headaches 
Table 1 - Respondent's demographic characteristics ( $N=3171)$.

\begin{tabular}{lc}
\hline Characteristics & $\mathbf{n}(\%)$ \\
\hline Working in health care sector? & $2347(74.0)$ \\
No & $824(26.0)$ \\
Yes & \\
Gender & $1078(46.0)$ \\
Female & $1263(54.0)$ \\
Male & \\
Age & $1578(67.4)$ \\
29 and Below & $669(28.6)$ \\
30 to 49 & $94(4.0)$ \\
50 and Above & \\
Marital status & $1486(63.5)$ \\
Single & $797(34.0)$ \\
Married & $41(1.8)$ \\
Divorce & $17(0.7)$ \\
Widow & \\
Region & $1023(43.7)$ \\
Middle & $457(19.5)$ \\
Western & $552(23.6)$ \\
Eastern & $167(7.1)$ \\
North & $142(6.1)$ \\
South & \\
Education & $1161(49.6)$ \\
Diploma and below & $1180(50.4)$ \\
Bachelor degree and higher & \\
Are you a smoker & $415(17.7)$ \\
Current user & $1813(77.4)$ \\
Not a user & $113(4.8)$ \\
Former smoker & \\
Do you consume alcohol & $2254(96.3)$ \\
No & $87(3.7)$ \\
Yes & \\
Knowledge about head and neck cancer & \\
Not at all knowledgeable & $1564(66.8)$ \\
Not very knowledgeable & $565(24.1)$ \\
Somewhat knowledgeable & $161(6.9)$ \\
Very knowledgeable & \\
Extremely knowledgeable & \\
& \\
\hline & \\
\hline
\end{tabular}

were not a symptom, while less than one-quarter recognize their pain $(19.4 \%)$ or a sore throat $(16.9 \%)$ as symptom. The knowledge of risk factors involved in HNCs, specifically tobacco and excessive alcohol consumption, were shown to be significantly different depending on gender $(p=0.002)$, marital status $(p=0.006)$, education $(p=0.007)$, and age $(p=0.037)$ (Table 2). Likewise, the knowledge of HPV infection varied significantly by gender $(p=0.003)$, marital status $(p=0.005)$, education $(p=0.002)$, and age $(p=0.036)$. No significant differences were seen for the risk factor of prolonged exposure to the sun based on demographics. Furthermore, the results showed that males (81\%) had better knowledge regarding tobacco and excessive alcohol use as risk factors, while females $(21.8 \%)$ were more knowledgeable on HPV infection as a risk factor.

Respondents who were single $(80.3 \%)$ had better knowledge regarding tobacco and excessive alcohol use as a risk factor, while those who were divorced (29.3\%) were more knowledgeable on HPV infection as a risk factor. Additionally, respondents who had a diploma $(82.6 \%)$ had more knowledge regarding tobacco and excessive alcohol use as a risk factor. Older respondents $(88.9 \%)$ were more aware in using tobacco and excessive alcohol are risk factors for developing HNCs (Table 3).

Knowledge of the relationship between HPV and HNC was shown to be significantly associated with marital status $(p=0.018)$, specifically for those who were widowed (11.8\%). However, no significant association was seen regarding the knowledge of a vaccine against HPV based on demographics.

Discussion. Most cases of HNC are detected at later stages owing to various factors. A common reason is

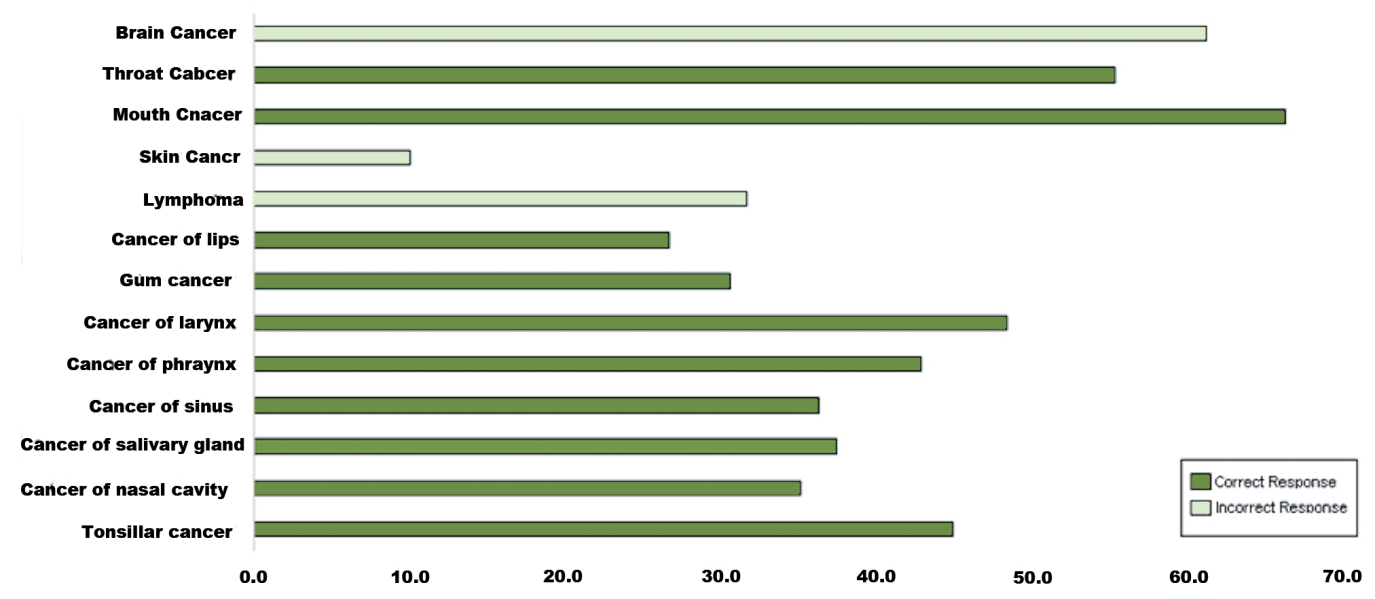

Figure 1 - Respondents' knowledge of cancers, including oral, head, and neck cancers. 


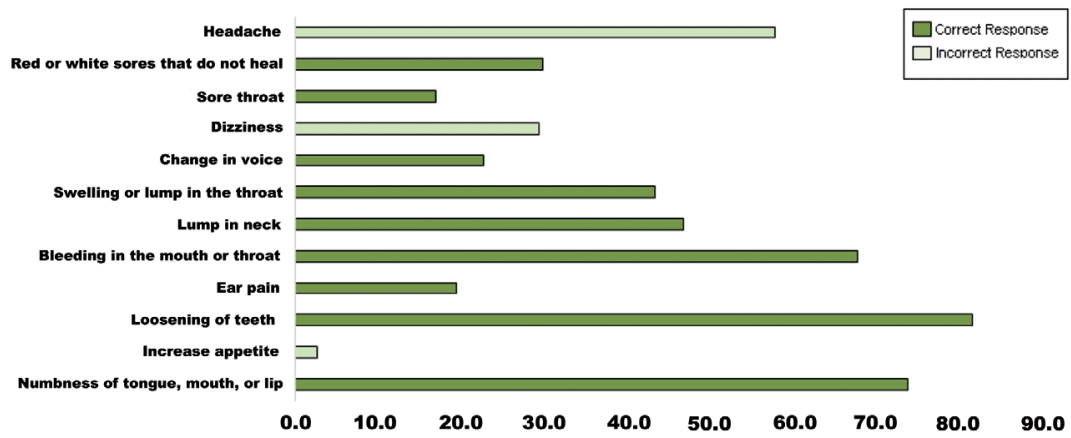

Figure $\mathbf{2}$ - Respondents' knowledge of the symptoms associated with oral, head, and neck cancers.

Table 2 - Respondent awareness of risk factors of head and neck cancer.

\begin{tabular}{|c|c|c|c|c|c|c|}
\hline \multirow[t]{2}{*}{ Characteristics } & \multicolumn{2}{|c|}{$\begin{array}{l}\text { Tobacco and excessive } \\
\text { alcohol consumption }\end{array}$} & \multicolumn{2}{|c|}{ HPV Infection } & \multicolumn{2}{|c|}{$\begin{array}{l}\text { Prolonged exposure } \\
\text { in the sun }\end{array}$} \\
\hline & $\%$ & $p$-value & $\%$ & $p$-value & $\%$ & $p$-value \\
\hline \multicolumn{7}{|l|}{ Gender } \\
\hline Female & 75.7 & \multirow{2}{*}{0.002} & 21.8 & \multirow{2}{*}{0.003} & 2.5 & \multirow{2}{*}{0.390} \\
\hline Male & 81.0 & & 17.0 & & 2.0 & \\
\hline \multicolumn{7}{|l|}{ Age } \\
\hline 29 and Below & 80.2 & \multirow{3}{*}{0.018} & 17.6 & \multirow{3}{*}{0.013} & 2.2 & \multirow{3}{*}{0.997} \\
\hline 30 to 49 & 75.0 & & 22.7 & & 2.2 & \\
\hline 50 and Above & 75.5 & & 22.3 & & 2.1 & \\
\hline \multicolumn{7}{|l|}{ Marital Status } \\
\hline Single & 80.3 & \multirow{4}{*}{0.039} & 17.4 & \multirow{4}{*}{0.019} & 2.2 & \multirow{4}{*}{0.575} \\
\hline Married & 75.7 & & 22.1 & & 2.3 & \\
\hline Divorce & 70.7 & & 29.3 & & 0.0 & \\
\hline Widow & 76.5 & & 17.6 & & 5.9 & \\
\hline \multicolumn{7}{|l|}{ Region } \\
\hline Middle & 79.2 & \multirow{5}{*}{0.671} & 19.2 & \multirow{5}{*}{0.963} & 1.7 & \multirow{5}{*}{0.085} \\
\hline Western & 79.2 & & 18.4 & & 2.4 & \\
\hline Eastern & 76.4 & & 19.9 & & 3.6 & \\
\hline North & 77.8 & & 20.4 & & 1.8 & \\
\hline South & 81.0 & & 18.3 & & 0.7 & \\
\hline \multicolumn{7}{|l|}{ Education } \\
\hline Diploma and below & 81.3 & \multirow{2}{*}{0.001} & 16.3 & \multirow{2}{*}{0.000} & 2.4 & \multirow{2}{*}{0.535} \\
\hline Bachelor degree and higher & 75.8 & & 22.1 & & 2.0 & \\
\hline
\end{tabular}

that patients cannot identify the early signs of HNCs. ${ }^{10}$ Therefore, improving the knowledge, awareness, and attitude of the general population towards HNCs will ameliorate cancer prognosis and allow for earlier diagnosis. Studies investigating awareness and knowledge of this topic among the general Saudi population are scarce. Herein, we shed light on this public health concern through a population-based analysis. The analysis revealed that most of the study respondents were not knowledgeable on HNCs. Most participants incorrectly believed that headache is not a symptom. In terms of the risk factors, males showed higher awareness of tobacco and excessive alcohol as risk factors, while females were more knowledgeable on $\mathrm{HPV}$ infection.

In our study, there was an alarming number of subjects who perceived themselves as having poor knowledge of HNC (66.8\%). It is noteworthy that various countries have shown low rates of awareness regarding HNCs, such as Jordan (45.6\%) and the United Kingdom (56\%). ${ }^{11}$ In contrast, some countries have reported higher rates of awareness, including Australia (79\%), Sri Lanka (95\%), the United States (84.5\%), and Yemen (71.5\%). ${ }^{12,13}$ It has been noted that the level of public awareness is higher in regions where 
Table 3 - Respondent knowledge of Human Papillomavirus and its relationship to head and neck cancer.

\begin{tabular}{|c|c|c|c|c|}
\hline \multirow[t]{2}{*}{ Characteristics } & \multicolumn{2}{|c|}{$\begin{array}{l}\text { Virus HPV that causes cervical cancer } \\
\text { is also associated with throat cancer }\end{array}$} & \multicolumn{2}{|c|}{$\begin{array}{l}\text { Did you know that there is a } \\
\text { vaccine against the virus HPV? }\end{array}$} \\
\hline & $\%$ & $p$-value & $\%$ & $p$-value \\
\hline \multicolumn{5}{|l|}{ Gender } \\
\hline Female & 4.9 & \multirow{2}{*}{0.459} & 7.1 & \multirow{2}{*}{0.312} \\
\hline Male & 4.3 & & 6.0 & \\
\hline \multicolumn{5}{|l|}{ Age } \\
\hline 29 and below & 4.2 & \multirow{3}{*}{0.241} & 6.5 & \multirow{3}{*}{0.995} \\
\hline 30 to 49 & 5.7 & & 6.4 & \\
\hline 50 and above & 3.2 & & 6.4 & \\
\hline \multicolumn{5}{|l|}{ Marital Status } \\
\hline Single & 3.8 & \multirow{4}{*}{0.090} & 6.6 & \multirow{4}{*}{0.986} \\
\hline Married & 5.8 & & 6.3 & \\
\hline Divorce & 4.9 & & 7.3 & \\
\hline Widow & 11.8 & & 5.9 & \\
\hline \multicolumn{5}{|l|}{ Region } \\
\hline Middle & 3.7 & \multirow{5}{*}{0.272} & 6.4 & \multirow{5}{*}{0.532} \\
\hline Western & 4.4 & & 6.1 & \\
\hline Eastern & 5.6 & & 6.0 & \\
\hline North & 4.8 & & 7.2 & \\
\hline South & 7.0 & & 9.9 & \\
\hline \multicolumn{5}{|l|}{ Education } \\
\hline Diploma and below & 4.3 & \multirow{2}{*}{0.544} & 6.4 & \multirow{2}{*}{0.817} \\
\hline Bachelor degree and higher & 4.8 & & 6.6 & \\
\hline & HPV: hun & virus & & \\
\hline
\end{tabular}

HNCs are prevalent, such as India and Sri Lanka. ${ }^{12,13}$ It is plausible that the low level of knowledge and awareness in Saudi Arabia is due to the relative rarity of HNCs as well as insufficient public health education. ${ }^{14}$

Notably, our analysis revealed that $57.8 \%$ of study respondents incorrectly stated that headaches are not a symptom of HNCs, and only $19.4 \%$ appropriately recognize their pain and sore throat as symptoms. In 2015, a similar study showed that Saudi people have very low knowledge concerning identification of clinical features of HNCs. ${ }^{14}$ The authors deduced that less than $25 \%$ recognized red or white patches as early signs of oral cancer, while only $30 \%$ were aware that a non-healing ulcer was a symptom of cancer. ${ }^{14}$ Interestingly, similar findings have been observed in other countries, which indicates a lack of information provided by healthcare professionals. ${ }^{13,15,16}$ Of note, the lack of general recognition of the early signs of HNCs could prevent disease diagnosis and affect overall survival. Therefore, enhancing the general public's education and sensibility towards HNCs will allow for prompt diagnosis and effective management. ${ }^{17}$

Our study revealed that there was insufficient knowledge concerning HNC risk factors. Alcohol and tobacco use were identified as potential risk factors by most of the study participants, while a smaller percentage were aware of the risks of HPV and sun exposure. This is consistent with a similar study that was conducted in Saudi Arabia, wherein $80 \%$ of the respondents recognized tobacco use as a risk factor, and only a small number were aware of the risk of old age, alcohol consumption, and sun exposure. ${ }^{14}$ Similarly, previous reports have shown that there is a higher general knowledge of tobacco as a risk factor in comparison with other possible risk factors. ${ }^{11,13}$ We hypothesize that the greater knowledge of tobacco use as a risk factor could be attributed to campaigns warning of the various dangers of smoking. This may support the promising role of similar campaigns to raise awareness of other potential negligent risk factors.

Several baseline demographics may affect the general knowledge and awareness of HNCs. In our study, older respondents were more aware of tobacco use and alcohol consumption as potential risk factors of HNCs. In addition, males had greater knowledge regarding tobacco use and excessive alcohol use as risk factors, while females were more knowledgeable of HPV infection as a possible risk factor. It has been reported by multiple studies that the level of knowledge on HNCs was affected by age and gender. ${ }^{11,14,18}$ However, in a published study, the authors reported no significant differences in the knowledge level between 
different age groups. ${ }^{14}$ Furthermore, participants with a diploma had greater knowledge regarding tobacco and excessive alcohol use as a potential risk factor. Similarly, in a Saudi study, there was a significant association between the level of knowledge and education status $(p<0.01)$. Participants who had completed high school or university had the greatest knowledge levels, while illiterate respondents had the lowest knowledge scores. ${ }^{14}$ In addition, these findings were supported by the results of different studies. ${ }^{11,13,18}$ While this study included a large number of respondents, future large-scale studies are recommended to allow for further generalizability and reliability of our findings. Another limitation that may manipulate the study results was the format of the questions; different word selection may alter the meaning. Nonetheless, this study highlighted and provided basic data for one of the major public health concerns.

In conclusion, this study revealed that there was a lack of knowledge and awareness of the clinical features and risk factors of HNCs among the Saudi population. Thus, public health authorities are urged to introduce prompt preventive measures, such as periodic screening programs for HNCs. In addition, public educational campaigns would aid in enhancing knowledge and understanding of HNCs among the Saudi population.

Further and more importantly, mass media educational programs should promote public awareness of HNCs through television, radio, and newspapers. Such recommendations could assure earlier identification of HNCs among the general population as well as improve disease survival and treatment outcomes.

Acknowledgment. The authors are grateful for the support by the Deanship of Scientific Research at Prince Sattam Bin Abdulaziz, University, Alkharj, Saudi Arabia. The authors would alsolike to thank SCRIBENDI (www.scribendi.com) for English language editing.

\section{References}

1. Bray F, Ferlay J, Soerjomataram I, Siegel RL, Torre LA, Jemal A. Global cancer statistics 2018: GLOBOCAN estimates of incidence and mortality worldwide for 36 cancers in 185 countries. CA Cancer J Clin 2018; 68: 394-424.

2. Alhazzazi TY, Alghamdi FT. Head and neck cancer in Saudi Arabia: a systematic review. Asian Pac J Cancer Prev 2016; 17 : 4043-4048.

3. Mehanna H, Paleri V, West CML, Nutting C. Head and neck cancer-Part 1: epidemiology, presentation, and preservation. Clin Otolaryngol 2011; 36: 65-68.
4. Datema FR, Ferrier MB, van der Schroeff MP, Baatenburg de Jong RJ. Impact of comorbidity on short-term mortality and overall survival of head and neck cancer patients. Head Neck 2010; 32: 728-736.

5. Sankaranarayanan R, Ramadas K, Thara S, Muwonge R, Thomas G, Anju G, et al. Long term effect of visual screening on oral cancer incidence and mortality in a randomized trial in Kerala, India. Oral Oncol 2013; 49: 314-321.

6. Luryi AL, Yarbrough WG, Niccolai LM, Roser S, Reed SG, Nathan C-AO, et al. Public awareness of head and neck cancers. JAMA Otolaryngol Head Neck Surg 2014; 140: 639-646.

7. Kim L, King T, Agulnik M. Head and neck cancer: changing epidemiology and public health implications. Oncology (Williston Park) 2010; 24: 915-919, 924.

8. Sturgis EM, Ang KK. The epidemic of HPV-associated oropharyngeal cancer is here: is it time to change our treatment paradigms? J Natl Compr Canc Netw 2011; 9: 665-673.

9. Chaturvedi AK, Engels EA, Pfeiffer RM, Hernandez BY, Xiao W, Kim E, et al. Human papillomavirus and rising oropharyngeal cancer incidence in the United States. J Clin Oncol 2011; 29: 4294-4301.

10. Macleod U, Mitchell ED, Burgess C, Macdonald S, Ramirez AJ. Risk factors for delayed presentation and referral of symptomatic cancer: evidence for common cancers. Br J Cancer 2009; 101: S92-S101.

11. Hassona Y, Scully C, Abu Ghosh M, Khoury Z, Jarrar S, Sawair F. Mouth cancer awareness and beliefs among dental patients. Int Dent J 2015; 65: 15-21.

12. Ariyawardana A, Vithanaarachchi N. Awareness of oral cancer and precancer among patients attending a hospital in Sri Lanka. Asian Pac J Cancer Prev 2005; 6: 58-61.

13. Agrawal M, Pandey S, Jain S, Maitin S. Oral cancer awareness of the general public in Gorakhpur city, India. Asian Pac J Cancer Prev 2012; 13: 5195-5199.

14. Al-Maweri SA, Tarakji B, Alsalhani AB, Al-Shamiri HM, Alaizari NA, Al Sakran Altamimi M, et al. Oral cancer awareness of the general public in Saudi Arabia. Asian Pac J Cancer Prev 2015; 16: 3377-3381.

15. Tadbir AA, Ebrahimi H, Pourshahidi S, Zeraatkar M. Evaluation of levels of knowledge about etiology and symptoms of oral cancer in Southern Iran. Asian Pac J Cancer Prev 2013; 14: 2217-2220.

16. Devadiga A, Prasad KVV. Knowledge about oral cancer in adults attending a dental hospital in India. Asian Pac J Cancer Prev 2010; 11: 1609-1613.

17. Al Dubai SAR, Ganasegeran K, Alabsi AM, Alshagga MA, Ali RS. Awareness and knowledge of oral cancer among university students in Malaysia. Asian Pac J Cancer Prev 2012; 13: $165-168$.

18. Ghani WMN, Doss JG, Jamaluddin M, Kamaruzaman D, Zain RB. Oral cancer awareness and its determinants among a selected Malaysian population. Asian Pac J Cancer Prev 2013; 14: 1957-1963. 